LOCAL: Universidade Federal do Rio Grande do Sul

NÍVEL: Mestrado

BANCA EXAMINADORA: Alfredo Gui Ferreíra (orientador) - UFRGS

Maria Irene de Moraes-Fernandes - CNPT - EMBRAPA

Regina Ramos Termignoni - UFRGS

Sandra Milach - UFRGS

Miguel Pedro Guerra - UFSC

RESUMO: A cultura de anteras tem sido largamente utilizada para obtenção de linhagens duplo-haplóides homozigotas em apenas uma geração ao invés das sete requeridas pelos programas convencionais de melhoramento. A cevada é uma das espécies cultivadas para a qual esta técnica encontra-se bem estabelecida embora, a resposta varie grandemente em função do genótipo e das condições ambientais de cultivo das plantas doadoras. Portanto, para empregar esta técnica como apoio ao melhoramento, é necessário adaptar meios e métodos para satisfazer os requerimentos específicos de cada material. $\mathrm{O}$ objetivo deste trabalho foi estudar a capacidade androgenética de híbridos entre cultivares e linhagens brasileiras de cevada e estabelecer um protocolo eficiente de regeneração de duplo-haplóides em número suficiente para viabilizar a sua utilização. Dois meios de cultura foram utilizados para indução de androgênese, N6 e MS, com pequenas modificações. A eficiência dos tratamentos foi avaliada através da frequiência de anteras responsivas e de regeneração de plantas verdes, porcentagem de albinismo e duplicação espontânea. Foi feita uma análise citológica e histológica no decorrer da cultura com o intuito de compreender melhor a gênese dos duplo-haplóides produzidos in "vitro". Os resultados mostram que a porcentagem média de anteras responsivas no meio N6 (30,32\%) foi maior do que no meio MS $(6,39 \%)$. Observou-se uma considerável influência do genótipo dos pais utilizados nos cruzamentos: alguns têm maior capacidade androgenética, ou por apresentarem um elevado número de anteras responsivas, ou por regenerarem plantas com maior freqüência. Diferentes genótipos diferem, também, quanto à freqüiência de albinismo e duplicação espontânea entre as plantas regeneradas. A análise citológica e histológica dos grãos-de-pólen confirmou a adoção de um padrão esporofítico de desenvolvimento, através de mitoses subseqüentes que levam à formação de grãos-de-pólen multicelulares, em um primeiro momento, e à formação de embriões ou de massas celulares desorganizadas, os calos, logo a seguir. Estas estruturas diferenciaram-se no próprio meio de indução, dando origem a plantas verdes e albinas. Um total de 192 plantas duplo-haplóides, originadas de diferentes genótipos, foram cultivadas até a produção de grãos. As sementes foram coletadas, multiplicadas e estão sendo avaliadas agronomicamente.

\title{
Universidade Federal de São Carlos
}

TÍTULO: Alguns aspectos de estrutura e comparação entre três paratudais no Pantanal de MirandaMS.

AUTOR: $\quad$ Ademir Kleber Morbeck de Oliveira

DATA: $\quad$ agosto de 1993

LOCAL: Departamento de Botânica - PPG-ERN/UFSCar

NÍVEL: $\quad$ Mestrado

BANCA EXAMINADORA: João Juares Soares (orientador) - UFSCar

José Antonio P.V. de Moraes - UFSCar

Tereza Cristina S. Pagotto - UFMS

RESUMO: O presente trabalho apresenta como objetivo principal estudar uma formação savanóide típica do Pantanal de Miranda, o paratudal, considerando seus aspectos quantitativos e qualitativos, tais como densidade, frequência, similaridade entre as áreas. O local de estudo está localizado no município de Corumbá-MS, em uma região conhecida como Passo do Lontra. A coleta de dados foi feita em três áreas, de características fisionômicas diferentes, mas com a predominância de Tabebuia caraiba. Foi utilizado 
o método das parcelas, tanto para a vegetação arbórea $(10 \times 10 \mathrm{~m})$ como para vegetação herbácea $(30 \times 30 \mathrm{~cm})$. Os resultados obtidos indicam que a vegetação herbácea muda de acordo com a época do ano. predominando uma espécie na cheia (Paspalum hỵdriphilum) e outra na seca. A vegetação é dominada por uma espécie, T. caraiba, que forma uma paisagem homogênea, mas sofre variações estruturais nas diferentes áreas, que provavelmente são resultado de diferentes épocas de colonização, originando árvores de diferentes portes na mesma área. Provavelmente este tipo de savana é resultado de três diferentes fatores que atuam conjuntamente, o edáfico, a inundação e o fator antrópico.

TíTULO: Curso diário e sazonal das trocas gasosas e potencial hídrico foliar em três espécies lenhosas do cerrado: Anacardium nanum St. Hill, Andira humilis Marth ex. Benth e Eriotheca gracilipes (K. Schum) A. Robins.

AUTOR: $\quad$ Silvia Sanches Kanno

DATA: dezembro de 1993

LOCAL: Departamento de Botânica - PPG-ERN/UFSCar

NÍVEL: $\quad$ Mestrado

BANCA EXAMINADORA: José Antonio P.V. de Moraes (orientador) - UFSCar

Sonia Cristina J.G. de A. Perez - UFSCar

Osvaldo Aulino da Silva - UNESP/Rio Claro-SP

RESUMO: Cursos diários das trocas gasosas e potencial hídrico foliar foram estudados em três plantas de cerrado: Anacardium nanum St. Hill, Andira humilis Marth ex. Benth, e Eriotheca gracilipes (K. Schum) A. Robins no ano de 1992. Observou-se diminuição nas trocas gasosas em um curto período de seca, resultante da diminuição na condutância estomática. Os maiores valores de condutância estomática decresceram de 1.04 para $0.19 \mathrm{~mol} \mathrm{~m}^{-2} \mathrm{~s}^{-1} \mathrm{em}$ Anacardium nanum, de 1.28 para $0.10 \mathrm{~mol} \mathrm{~m}^{-2} \mathrm{~s}^{-1} \mathrm{em}$ Andira humilis e de 1.13 para $0.18 \mathrm{~mol} \mathrm{~m}^{-2} \mathrm{~s}^{-1} \mathrm{em}$ Eriotheca gracilipes. Os valores de transpiração decresceram de 6.13 para $4.68 \mathrm{mmol} \mathrm{m}^{-2} \mathrm{~s}^{-1} \mathrm{em}$ Anacardium nanum, de 8.91 para $2.81 \mathrm{mmol} \mathrm{m}^{-2} \mathrm{~s}^{-1} \mathrm{em}$ Andira humilis e de 8.33 para $4.65 \mathrm{mmol} \mathrm{m}^{-2} \mathrm{~s}^{-1}$ em Erioteca gracilipes. Os valores de fotossíntese decresceram de 9.86 para $6.13 \mathrm{imol} \mathrm{m} \mathrm{m}^{-2} \mathrm{~s}^{-1} \mathrm{em} \mathrm{A.} \mathrm{nanum,} \mathrm{de} 11.5$ para $6.12 \mathrm{ìmol} \mathrm{m}^{-2} \mathrm{~s}^{-1} \mathrm{em} \mathrm{A}$. humilis e de 13.94 para $7.23 \mathrm{imol}$ $\mathrm{m}^{-2} \mathrm{~s}^{-1}$ em $E$. gracilipes. O potencial hídrico foliar não apresentou variação sazonal marcante, sendo observados valores um pouco menos negativos na época seca, provavelmente em função dos valores de condutância apresentados. Com base nos valores de potencial hídrico mínimo e outras caracterísitcas, como disposição da folha no ambiente, senescência foliar, grau de abertura estomática, discute-se as possíveis estratégias de resistência à seca.

TíTULO: Efeitos do ácido abscísico, potencial hídrico, temperatura e tratamentos para quebra de dormência na germinação de sementes de Diamorphandra mollis Benth .

AUTOR: $\quad$ Francisco Antonio Zpevák

DATA: $\quad$ agosto de 1994

LOCAL: Departamento de Botânica - PPG-ERN/UFSCar

NÍVEL: $\quad$ Mestrado

BANCA EXAMINADORA: Sonia Cristina J.G. de A. Perez (orientadora) - UFSCar

José Antonio P.V. de Moraes - UFSCar

Tereza Cristina Stocco Pagotto - UFMS

RESUMO: Dimorphandra mollis Benth (Leguminosae-Mimosoideae) é uma espécie arbórea dos cerrados brasileiros, útil na recuperação de áreas degradadas e como planta ornamental. Produz madeira, sementes e substâncias químicas potencialmente utilizáveis na indústria. Visando contribuir para o conhecimento biológico a respeito desta espécie foram estudados os efeitos da aplicação exógena de ácido abscísico, do potencial hídrico, da temperatura, da intensidade luminosa e de tratamentos para quebra de dormência na germinação de suas sementes. As sementes apresentam dormência imposta pelo tegumento que é superada escarificando-se as sementes com ácido sulfúrico concentrado durante uma hora. Utilizou-se 200 sementes 
para cada teste. as quais foram escarificadas, lavadas, dispostas em placas de Petri com papel de filtro umedecido por água deionizada ou pela respectiva solução-teste, e incubadas isotermicamente. A germinação foi aliviada diariamente tendo-se como critério o comprimento radicular $2 \mathrm{~mm}$. Constatou-se que esta espécie germina numa faixa de temperatura com valores mínimos entre $9^{\circ} \mathrm{C} \mathrm{e} 12^{\circ} \mathrm{C}$, máximos entre $39^{\circ} \mathrm{C}$ e $41^{\circ} \mathrm{C}$ e ótimos entre $27^{\circ} \mathrm{C}$ e $33^{\circ} \mathrm{C}$ e não houve germinação a $9^{\circ} \mathrm{C}$ nem a $42^{\circ} \mathrm{C}$. A velocidade de germinação das sementes desta espécie não e linearmente dependente da temperatura em toda a extensão de isotermas estudadas e, portanto, não segue a cinética de Arrhenius. A variação líquida ( $\ddot{A} H n=)$ da entalpia de ativação do processo germinativo atinge valores positivos maiores que $30 \mathrm{Cal} / \mathrm{mol}$ abaixo de $18^{\circ} \mathrm{C}$, valores negativos maiores que $30 \mathrm{Cal} / \mathrm{mol}$ acima de $33^{\circ} \mathrm{C}$ e valores inferiores a $112 \mathrm{Cal} / \mathrm{moll}$ na faixa entre $21^{\circ} \mathrm{C}$ e $30^{\circ} \mathrm{C}$ indicando que a limitação do processo germinativo é dada por processos de difusão na faixa de temperatura entre $21^{\circ} \mathrm{Ce} 30^{\circ} \mathrm{C}$, e, possivelmente por transições de fase, nas temperaturas extremas. Condições sombreadas são mais adequadas à germinação das sementes. O ácido abscísico em soluções de $10-5 \mathrm{M}$ até $10-4 \mathrm{M}$ diminui a germinabilidade, velocidade e sincronização do processo germinativo, sendo a germinação inibida em ABA $10-3 \mathrm{~m}$. O estresse hídrico reduziu a germinabilidade à medida em que o potencial hídrico foi diminuído de $-0,4 \mathrm{MPa}$ a $-0,6 \mathrm{MPa}$, mas não acarretou em mudanças significativas na velocidade ou na sincronização. No potencial hídrico $-0,7 \mathrm{MPa}$ as sementes não germinaram. A combinação do $\mathrm{ABA} 10-5 \mathrm{M}$ com os potenciais hídricos entre $-0,4 \mathrm{MPa}$ e $-0,6 \mathrm{MPa}$ diminuiu significativamente a velocidade de germinação das sementes mas não produziu alterações contínuas e significativas na germinabilidade nem na sincronização do processo germinativo. Os resultados foram discutidos considerando-se a possibilidade de que os efeitos destes fatores possam influenciar na germinação e no estabelecimento da espécie Dimorphandra mollis Benth em seu ambiente natural.

TÍTULO: Caracterização de três fisionomias do cerrado da Fazenda Canchin - São Carlos - SP. AUTOR: Alexandre Camilo da Silva

DATA: $\quad$ setembro de 1994

LOCAL: Departamento de Botânica - PPG-ERN/UFSCar

NÍVEL: Mestrado

BANCA EXAMINADORA: João Juares Soares (orientador) - UFSCar

José Antonio P.V. de Moraes - UFSCar

Waldir Mantovani - USP

RESUMO: A vegetação da reserva da Fazenda Canchin, localizada no município de São Carlos $\left(22^{\circ} 01^{\prime}\right.$ $\mathrm{S}$ e $47^{\circ} 53^{\prime} \mathrm{O}$ ). é tipicamente de cerrado e apresenta três formas desta vegetação (campo cerrado, cerrado e cerradão). Partindo de uma abordagem fisionômica, analisando-se com base em parâmetros fisionômicoestruturais, caracterizou-se as diferentes formas de cerrado. Os parâmetros utilizados foram: altura; tipo, pilosidade e textura das folhas; proteção das gemas; formas de vida e funcionalidade (caducidade). Os dados mostram que as áreas apresentam-se bem diferenciadas quanto aos limites de altura ( $2 \mathrm{~m}$ para o campo cerrado, $6,5 \mathrm{~m}$ para o cerrado e $11 \mathrm{~m}$ para o cerradão), quanto a distribuição das folhas simples e compostas (sendo que a porcentagem de folhas compostas aumenta a medida que se passa do cerradão para o campo cerrado), quanto à distribuição dos tamanhos foliares (onde todas as áreas apresentam uma concentração dos tipos micrófilos e mesófilos) e quanto à distribuição das classes de textura (todas as áreas possuem maior porcentagem de folhas esclerófilas).

TÍTULO: Estresse hídrico e trocas do $\mathrm{CO}_{2}$ gasoso e vapor d'água em plantas jovens envasadas de Stryphnodendron adstringens (Mart.)".

AUTOR: $\quad$ Ana Maria dos Santos Rocha

DATA: $\quad$ novembro de 1994

LOCAL: Departamento de Botânica - PPG-ERN/UFSCar

NÍVEL: Mestrado

BANCA EXAMINADORA: José Antonio P. V. de Moraes (orientador) - UFSCar

Sonia Cristina J. G. de A. Perez - UFSCar

João Domingos Rodrigues - UNESP - Botucatu - SP 
RESUMO: Neste trabalho foram estudadas as trocas gasosas do $\mathrm{CO}_{2}$ e vapor d'água de Stryphnodendron adstringens de 6 meses de idade, submetida a estresse hídrico induzido artificialmente por suspensão da rega. Os valores de potencial hídrico foliar foram correlacionados com os valores de trocas gasosas do $\mathrm{CO}_{2}$ e condutância estomática, obtidos nos 32 dias de experimento. A fotossíntese líquida, transpiração e potencial hídrico foliar tiveram seus valores diminuídos, drasticamente, a partir do $27^{\circ}$ dia de estresse hídrico, quando os valores de condutância estomática obtidos foram próximos de zero. O potencial hídrico foliar que limitou a fotossíntese líquida foi igual a - 2,7 MPa. As plantas previamente estressadas foram reidratadas, e após 48 horas se recuperaram totalmente, voltando a apresentar os mesmo valores de potencial hídrico foliar, condutância estomática e fotossíntese líquida, obtidos no início do experimento. $\mathrm{O}$ potencial osmótico foi medido antes e após o estresse hídrico, em folhas túrgidas, tendo diminuído de valor em aproximadamente $22 \%$ após o estressamento, indicando a ocorrência de ajustamento osmótico. Também foram estudadas as respostas da fotossíntese em relação a variação na intensidade luminosa através da realização de curvas de luz $\mathrm{X}$ fotossíntese, para plantas de $S$. adstringens nas idades de 1, 6 e 12 meses. Os valores de fotssíntese máxima (Amax), ponto de compensação à luz (PCL), e intensidade luminosa em que ocorre saturação da fotossíntese (IK), foram calculados nas 3 idades. Os resultados obtidos foram correlacionados com a idade da planta.

TíTULO: Tratamento pré-germinativos e aspectos ecofisiológicos na germinação de semente de Stryphnodendron polyphyllum Mart.

AUTOR: Mariângela Tambelini

DATA: dezembro de 1994

LOCAL: Departamento de Botânica - PPG-ERN/UFSCar

NÍVEL: $\quad$ Mestrado

BANCA EXAMINADORA: Sônia Cristina Juliano Gualtieri de A. Perez (orientadora) - UFSCar José Antonio P. V. de Moraes - UFSCar

Massanori Takaki - Dep. de Botânica - UNESP - Rio Claro

RESUMO: Foram estudados aspectos relativos à quebra de dormência e à germinação de sementes de Stryphnodendron polyphyllum, uma leguminosa de cerrado. Devido ao tegumento duro apresentado pelas sementes dessa espécie, o efeito restritivo à germinação é marcante. O tratamento pré-germinativo mais adequado para a quebra de dormência mecânica foi a escerificação, especialmente a química, com ácido sulfúrico durante 60 minutos. Para cada experimento foram utilizadas 200 sementes, divididas em 4 lotes de 50 sementes. A incubação foi feita em placas de Petri esterilizadas, forrradas com duas folhas de papel de filtro autoclavado, em temperatura de $30^{\circ} \mathrm{C}$. A leitura foi realizada diariamente, considerando-se o comprimento radicular $2 \mathrm{~mm}$. A temperatura mínima determinada para a germinação dessa espécie esteve entre 5 e $10^{\circ} \mathrm{C}$, a faixa ótima entre 25 e $30^{\circ} \mathrm{C}$, e a temperatura máxima esntre 40 e $45^{\circ} \mathrm{C}$. A velocidade de germinação apresentou-se linearmente dependente da temperatura. A variação da entalpia líquida de ativação da germinaçã̃o $\left(\ddot{\mathrm{A}} H_{n}\right)$ apresentou valores absolutos menores que $12 \mathrm{Kcal} / \mathrm{mol}$ entre 20 e $30^{\circ} \mathrm{C}$, e maior que $30 \mathrm{Kcal} / \mathrm{mol}$ a partir de $35^{\circ} \mathrm{C}$. Os menores valores de entropia informacional ocorreram entre 25 e $30^{\circ} \mathrm{C}$, mostrando maior sincronização do processo germinativo nestas temperaturas. Sementes não embebidas resistiram à estresses de áte $70^{\circ} \mathrm{C}$ por $48 \mathrm{~h}$ sem apresentarem redução da germinabilidade ou da velocidade de germinação. Sementes embebidas foram sensíveis à $50^{\circ} \mathrm{C}$ por $24 \mathrm{~h}$. $\mathrm{O}$ estresse hídrico provocou redução significativa na porcentagem de germinação à partir de $-0,9 \mathrm{MPa}$, com a utilização do agente osmótico manitol, e à partir de $-0,5 \mathrm{MPa}$ com a utilização de PEG. A velocidade de germinação sofreu redução significativa à partir de $-0,1 \mathrm{MPa}$ tanto com manitol como com PEG. Semntes de Stryphnodendron polyphyllum se mostraram indiferentes à luz. A utilização de concentração de alumínio até $4,0 \mathrm{~m} . e . / 100 \mathrm{ml}$ de solução não interferiu na germinação. Estas sementes também foram muito resistentes ao envelhecimento, não apresentando variação significativa na porcentagem ou na velocidade de germinação, mesmo quando submetidas ao envelhecimento precoce durante 32 dias. 
TíTULO: Estudo fitossociológico comparativo entre duas áreas com mata de encosta no Rio Grande do Sul.

AUTOR: João André Jarenkow

DATA: $\quad$ novembro de 1994

LOCAL: Departamento de Botânica - PPG-ERN/UFSCar

NÍVEL: Doutorado

BANCA EXAMINADORA: Maria Helena Antunes de Oliveira e Souza (orientador) -UFSCar

Sônia Cristina J. G. de Andrade Perez - UFSCar

João Juares Soares - UFSCar

Waldir Mantovani - USP

Jorge Luiz Waechter - UFRGS

RESUMO: Em duas áreas com mata nas encostas da Serra Geral, no Rio Grande do Sul, foram determinadas a composição florística e estrutura fitossociológica a partir de amostragens de lha, as quais proporcionam, também, meios para inferências sobre aspectos dinâmicos e fitogeográficos regionais. Em Morrinhos do Sul $\left(29^{\circ} 21^{\prime} 30\right.$ ' ' S e $49^{\circ} 58$ ' $35^{\prime}$ ' ' W, $440 \mathrm{~m}-480 \mathrm{~m}$ de altitude), foram amostrados 2822 indivíduos com $5 \mathrm{~cm}$ ou mais de diâmetro na altura do peito (DAP), pertencentes a 114 espécies, 84 gêneros e 44 gêneros e 25 famílias, com Actinostemon concolor, Euterpe edulis, Sorocea bonplandii. Pachystroma longifolium e trichilia claussenii, acumulando os maiores IVI. A similaridade florística mostrou-se baixa, avaliada tanto por índices qualitativos quanto quantitativos. A família Myrtaceae contribui com o maior número de espécies que, juntamente com Euphorbiaceae, Lauraceae e Arecaceae, acumulam percentagens consideráveis do IVI total, em ambos os trechos. Em Morrinhos do Sul destacam-se ainda Ruboaceae e Cyatheaceae e, em Vale do Sol, Moraceae e Meliaceae. Com a alteração no critério de inclusão para DAP a partir de $10 \mathrm{~cm}$, os indivíduos amostrados reduzem-se a cerca de $40 \%$, com Euterpe edulis, Nephelea setosa, Chrysophyllum viride, Tetrorchidium rubrivenium e Casearia sylvestris, assumindo os valores IVI em Morrinho do Sul e edulis, Actinostemon concolor, Trichilia claussenii, Pachystroma Longifolium e Hennecartia omphalandra em Vale do Sol. Sob este critério, apesar da redução na riqueza, a diversidadde florística é maior, estimada pelo índice de Shannon em 2,63 (nats) para Vale do Sol e 3,88 (nats) para Morrinhos do Sul, sendo esta uma das maiores registradas para o componente arbóreo na região. $\mathrm{O}$ enquadramento das espécies amostradas em categorias sucessionais nas quais ocorrem predominantemente, aliado à contribuição quantitativa de cada uma indica que ambos os trechos encontram-se em fases de préclimácica a climácica. Entre as populações mais abundantes, a análise da distribuição de diâmetros indica boa reposição de indivíduos, demonstrando processos de regeneração em andamento. Através da análise de agrupamentos, a mata de Vale do Sol liga-se àquelas ocorrentes ao longo das Bacias Hidrográficas dos Rios Paraná e Uruguai e a de Morrinhos do Sul com as matas da Encosta Atlântica reforçando a hipótese da expansão de espécies tropicais em direção sul por dois corredores distintos. A acentuada diferença na composição florística entre ambos os trechos, ao que parece, não pode ser atribuída a fatores climáticos e dáficos atuais. A análise da distribuição da vegetação atual aponta maior competitividade de espécies do corredor atlântico que, aparentemente, favorece sua expansão sobre trechos com Florestas Estacionais, com tendência a estabelecerem-se nessas áreas, se mantidas as condições climáticas hodiernas

\section{Universidade de São Paulo}

TÍTULO: Estudos morfoanatômicos dos órgãos vegetativos de dioscorea kuntiana.

AUTOR: Dalva Cassie Rocha

DATA: fevereiro de 1995

LOCAL: Universidade de São Paulo

NÍVEL: Mestrado 